\title{
BERDISCO SEBAGAI BENTUK PENGALAMAN PROSES PENGGARAPAN KARYA TARI
}

\author{
Oleh : I Nyoman Galih Adi Negara
}

\begin{abstract}
ABSTRAK
Berdisco merupakan judul dari karya tari ini. Disco berarti sebuah kegiatan berdansa di lantai dansa secara bersama-sama, berikan awalan ber- yang merujuk pada proses disco tersebut. Berdisco memiliki makna melakukan disco baik dalam tari, musik, dan busana, namun dalam karya ini merujuk pada proses bagaimna disco itu menjadi sebuah jati untuk berkarya. Karya ini menekankan pada proses pencarian dan menetapkan pilihan hingga berjuang untuk pilihan tersebut. Dahulu disco dianggap sangat tidak pantas untuk ditampilkan di publik karena dianggap merusak generasi. Bentuk tari, musik, dan busana yang digunakan oleh seniman disco dianggap tidak senonoh dan diluar dari aturan yang berlaku pada saat itu. Disco sangat kelam pada saat itu, apapun yang berbau disco dihancurkan hingga tidak tersisa. Disco dianggap membawa perubahan yang buruk bagi masyarakat pada saat itu.

Karya ini memiliki alur dramatik yang hampir mirip dengan situasi disco pada saat itu. Situasi tersebut dikaitkan dengan apa yang terjadi pada proses penggarapan karya tari ini. Proses yang sangat tidak mudah, karena disco dianggap kurang "keren". Padahal hingga saat ini disco masih setia diperdengarkan, ditayangkan, dan diaransemen ulang agar lebih menarik.

Karya tari Berdisco disajikan dengan menampilkan dua belas orang penari putra dan putri. Musik iringan yang digunakan pada karya ini adalah rekaman bentuk WAV dari midi. Busana yang berkilau, menghadirkan disco ball, dan aksesoris yang dikenakan penari dimaksudkan dapat mewakili disco.
\end{abstract}

kata kunci, disco, dan Berdisco, dan situasi

\begin{abstract}
Berdisco is the title of this masterpiece. Disco means a dance activities on the dance floor together each other, added "ber-" refer to disco proses. Berdisco meaning do disco in dance, music, or fashion style, but in this work refers to the proses of how disco became a identity. This masterpiece emphasize on proses to find a choice and struggle for that choice. Before disco considered inappropriate to show on public because it can damaging generations. Dance form, music, and fashion style was used by disco artist are considered not profanity and out of applicable rule in that era. Disco has a dark time, they destroyed anything about disco until no remaining. Disco considered to bring a bad change for society at that time.

This masterpiece has a dramatic flow is almost similar to situation at era. That situation related to what happens in the proses of this masterpiece. Perform productions proses is never easy, because disco concendered is not cool. Whereas until now they still played, dance, and listen disco. Berdisco displaying twelve male and female dancers. Musical accompaniment used are recording from midi. Blink costume design, displaying disco balls, and many disco setting, lighting they wearing.
\end{abstract}

Keyword : disco, Berdisco, and situation 


\section{PENDAHULUAN}

\section{A. Latar Belakang}

Karya tari Berdisco ini terinspirsi dari situasi saat diterimanya disco kembali oleh masyarakat. Disco dianggap tidak pantas untuk dipublikasikan karena gaya busana yang menyalahi aturan pada masa itu, lirik yang vulgar, dan sangat berdekatan dengan narkotika serta identik dengan pergaulan bebas (Film Dokumenter "Disco-Spinning The Story Part 7”.). Pada 12 Juni 1979 disco mengalami masa suram yang benar-benar tidak masuk akal. Stadion Comiskey Parrk pada pertandingan bisbol Doubleheader antara Chicago White Sox dan Detroid Tiger adalah tempat dimana gerakan anti disco memuncak, acara tersebut bernama Disco Demolition Night. Acara tersebut diketuai oleh disc jockey (DJ) radio yang bernama Steve Dhl dibantu direktur promosi Chicago White Sox bernama Mike Veek yang sangat tidak senang dengan disco sering mengatakan "Disco Sucks!" sepanjang siaran (Wikipedia, pembaharuan 2013, "Disko", Wikimedia Project, https://id.wikipedia.org/wiki/Disko). Hal - hal yang berbau disco dihancurkan, kerusuhan terjadi dimana-mana, musik disco mulai memudar, dan disco mulai tenggelam. Pada awal tahun 1980-an bangkit kembali diwali dengan lagu berjudul I Will Survive yang dinynyikan oleh Gloria Gaynor. Lagu tersebut sangat melegenda dan tetap diperdengarkan hingga sekarang, bukan hanya karena lirik dan musiknya namun cerminan dari bangkitnya disco (https://id.wikipedia.org/wiki/Disko).

Diadaptasi dari masa kelam hingga diterima kembali, penata mencoba mengkaitkan alur tersebut dengan bagaiman proses penggarapan tugas akhir ini. Proses yang tidak mudah, karena disco yang dianggap tidak keren dan ketinggalan jaman. Padahal hingga sekarang disco masih tetap diperdengarkan dan ditarikan, disiarkan di televisi, hingga digarap ulang menjadi sesuatu yang baru. Awalnya disco mulai populer di Amerika pada awal tahun 1941 (Free Genre Of
Music dalam artikel berjudul "Sejarah Asal Mula Musik Disco". 2003, facebook.co.id ), dan kata disco itu sendiri berasal dari bahasa Prancis yaitu discotheque yang berarti tempat berdansa atau lantai dansa. Tidak hanya di Amerika, disco juga sampai ke Indonesia yang dipelopori oleh Guruh Soekarno Putra yang menciptakan lagu bernuansa disco yaitu Keranjingan Disco. Lagu tersebut dinyanyikan oleh Johny Lewerisa pada tahun 1976 yang sangat populer pada saat itu (Radio Fm, Seleksi Pop Karya Original Guruh Soekarno Putra, indolawas.blogspot.co.id.). Hingga sekarang disco masih senantiasa dipergunakan, setidaknya ada unsur disco pada gerak tari maupun musik di Indonesia yang bersifat komersial atau pola ritme yang sangat mirip dengan disco.

\section{B. Rumusan Ide Penciptaan}

Disco adalah jenis tari populer yang kerap ditarikan untuk acara komersial dan juga untuk lomba tari tingkat amatir hingga professional. Disco dijadikan materi utama penggarapan karya tari ini dengan memasukkan unsur dramatik untuk menggambarkan situasi disco pada saat terpuruk hingga berjaya. Dari uraian latar belakang penciptaan, maka bisa diambil beberapa pertanyaan kreatif sebagai berikut :

1. Bagaimana mengolah tari disco menjadi sebuah tari yang memiliki alur dramatik?

2. Bagaimana melakukan pengembangan gerak dasar disco menjadi disco yang baru dengan tidak menghilangkan esensi dari disco tersebut?

3. Bagaimana memunculkan suasana disco di panggung proscenium, dengan pengolahan gerak, busana, penari, hingga artistik?

Beberapa pertanyaan kreatif tersebut menghasilkan rumusan ide penciptaan dari karya tari ini. Berpijak dari gerak dasar tari disco yang populer pada tahun 1970an hingga 2000an, akan dihadirkan disco yang berbeda dari sebelumnya namun tetap dalam esensi 
disco yang kental baik dari visual maupun pendukung lainnya. Karya tari ini akan menggunakan large group composition yang dibagi menjadi dua kelompok. Kelompok penari utama berjumlah sepuluh orang di antaranya lima penari putra dan lima penari putri, penari utama adalah penari yang muncul dari awal hingga akhir karya. Kelompok kedua berjumlah dua orang yaitu dua penari putra, yang muncul pada bagian akhir.

Pada bagian kedua karya Berdisco ini, penggambaran tentang disco yang dibenci dan ditinggalkan dengan memanfaatkan delapan penari yang berada di up left hingga up right keluar dari panggung satu per satu hingga tinggal tiga penari yang menggambarkan bahwa orang-orang membenci disco, diikuti dengan ketiga penari terakhir yang pada akhirnya ikut meninggalkan disco karena menyadari bahwa disco menyebabkan kekacauan. Kemudian muncul satu penari melakukan solo berperan sebagai disco itu sendiri yang membicarakan tentang kesendirian karena ditinggalkan. Saat penggambaran bangkitnya disco, dimainkan lagu "I Will Survive" dan penari yang lainnya mulai menari bersama lagi. Pada akhir karya dua penari tambahan menari bersama melakukan flash mob. Gerakan sederhana dilakukan dengan rampak simultan, untuk menunjukkan bahwa disco telah diterima hingga sekarang.

\section{A. Tujuan dan Manfaat}

Dalam setiap karya pasti ada tujuan dan manfaat, karya ini dibuat baik bagi penata maupun penonton. Adapun manfaat dan tujuan karya ini dibuat di antaranya :

\section{Tujuan :}

a. Menciptakan karya baru berpijak pada tari disco, dengan alur dramatik yang mengadaptasi situasi disco sebagai dasar penciptaan karya.

b. Mengembangkan dengan cara mengeksplorasi gerak dasar disco yang sudah ada dan menyusunnya menjadi koreografi kelompok. c. Memunculkan suasana disco pada panggung prosenium dengan mengolah gerak, busana, penari, hingga artistik.

\section{Manfaat :}

a. Mendapat wawasan baru tentang awal terbentuknya tari disco dan musik disco.

b. Bisa melakukan pengolahan tari disco menjadi tari disco baru dengan memasukkan alur dramatik.

c. Dapat melakukan pengembangan gerak dasar disco menjadi tari baru namun tidak menghilangkan esensi dari disco tersebut.

\section{Pembahasan}

Karya Berdisco ini tercetus karena adanya gagasan atas fenomena yang terjadi, dari rangsang kinestetik, hingga pengalaman pribadi. Pengalaman pernah bekerja sebagai penari di klub disco bernama "Bouny Discotheque" yang berada di Legian Kecamatan Kuta, Kabupaten Badung, Propinsi Bali. Belajar menari disco bersama penari yang hali dengan tehnik disco, dan menarikannya di panggung klub tersebut sangat melekat dalam benak penata. Berada di lingkup penari yang serius dalam mencari hingga menyamakan persepsi gerak adalah kenyamanan tersebdiri bagi penata. Selain itu penata juga tergugah karena melihat video unduhan dari Youtube, yaitu konser musik oleh Madonna pada tahun 2006 bertepat di London. Gerak dasar disco tahun 1970-an muncul jelas digabungkan dengan gerak tari pop masa kini. Video tersebut juga menampilkan gerak beroasangan dan dilakukan berkelompok, tampak jelas penggunaan akrobatik yaitu lifting pada beberapa bagian tari.

Tema yang diangkat dalam karya ini adalah sebuah proses pembuatan sebuah karya yang pasti tidaklah segampang membalikkan telapak tangan. Judul Berdisco diambil karena lebih merujuk pada sebuah proses sebuah proses bukan hasil. Penulisan "disco" tidak memakai huruf "k", karena merujuk pada dimana disco tersebut lahir dan dinamika jatuh 
bangunnya terjadi. Karya tari ini lebih menekankan pada pengembangan gerak dan motif dasar tari disco. Mencari kemungkinan gerak disco yang bisa didapat dari gerak dan motif dasar disco sebelumnya. Dibagi menjadi empat adegan yaitu Introduksi sebagai perkenalan apa saja yang akan muncul pada adegan selanjutnya, namun hanya cuplikan saja. Adegan 1 dimunculkan disco pada dua jaman berbeda antara jaman 80-an daengan jaman sekarang. Adegan 2 adalah bagian dengan memunculkan cerita disco ditinggalkan, pada bagian ini tidak begitu ramai agar terfokus pada cerita yang ingin di sampaikan. Bagian akhir karya tari ni adalah Adegan 3 dimana menggambarkan kebangkitan dari disco dan diterima kembali di masyarakat. Pada akhir karya ini menggunakan lagu Madonna yang berjudul Give It To Me, lagu tersebut digunakan karena liriknya bermakna mengajak orang untuk bangkit dan menari. Selain lagu Maddona, lagu selanjutnya sebagai akhir adalah Celebration yang dinyanyikan oleh The Gangs yang bermakna merayakan sebuah keberhasilan.

Metode adalah cara teratur yang digunakan untuk melaksanakan suatu pekerjaan agar tercapai sesuai dengan yang di kehendaki. Metode penciptaan tari bisa diartikan cara yang harus ditempuh untuk menciptakan sebuah karya tari. Setiap individu mempunyai caranya sendiri untuk menggarap tergantung pada pengetahuan, pendidikan, lingkungan, dan pengalaman yang dimiliki. Metode yang diaplikasikan dalam penciptaan ini adalah ekplorasi yang dilakukan oleh penata baik dari data hingga gerak. Selanjutnya improvisasi dilakukan langsung oleh penari dengan motivasi yang diberikan namun tidak keluar dari konsep disco. Setelah improvisasi dilakukan maka tahapan selanjutnya adalah evaluasi gerak yang akan digunakan, disini penata sudah mulai memperhitungkan kenyamanan gerak penari. Tahap akhir adalah komposisi, tahap ini mengkomposisi gerak yang telah dievaluasi dan dijadikan motif gerak. Tahap ini sangatlah tidak mudah karena harus memperhitungkan kenyamanan serta teba gerak penari agar mendapatkan hasil maksimal.

Karya tari ini menggunakan dua belas orang penari putra dan putri. Penari tersebut memiliki postur tubuh yang hampir mirip, dan kemampuan yang bisa dikatakan mampu untuk mengikuti disiplin gerak yang diberikan, walaupun sering terjadi salah presepsi. Untuk setiap gerakan penata memperhitungkan kenyamanan dan kemampuan penari agar penari tidak merasa terpaksa untuk melakukannya. Karena kenyamanan dalam menarikan tarian ini adalah hal utama dan ditekankan.

Karya tari ini diiringi music instrument digital interface (MIDI) yang ditata sendiri, menggunakan perangkat lunak Fruty Loop Producer Edition menjadikan musik terdengar menyerupai suara instrumen asli. Dimaksukkannya pola-pola dasar musik disco dimaksudkan untuk membangun suasana disco namun dengan rasa yang baru, seperti digabungkan dengan pola musik rock serta menggunakan suara power guitar.

Proses realisasi karya tari ini kurang lebih empat bulan dengan empat kali latihan dalam seminggu. Penata membaginya tiga hari untuk latihan koreografi, satu hari untuk olah tubuh dan cardiovagular untuk melatih stamina penari.

Karya tari ini dibuat bertujuan untuk menyuarakan bahwa menjadi berbeda itu indah, namun proses untuk mencapainya bukan hal yang mudah. Penata ingin mengatakan, dengan karya ini semua proses tidak akan menyenangkan namun bagaimana menjadikan proses itu nyaman dan bertahan apapun yang terjadi. Penata yakin ketika kita siap, yakin, dan dibarengi dengan doa, apapun tujuan kita pasti tercapai bagaimanapun cara dan prosesnya. 
JOGED

ISSN: $1858-3989$
I Nyoman Galih Adi Negara (BERDISCO SEBAGAI BENTUK PENGALAMAN PROSES PENGGARAPAN KARYA TARI)

\section{DOKUMENTASI :}

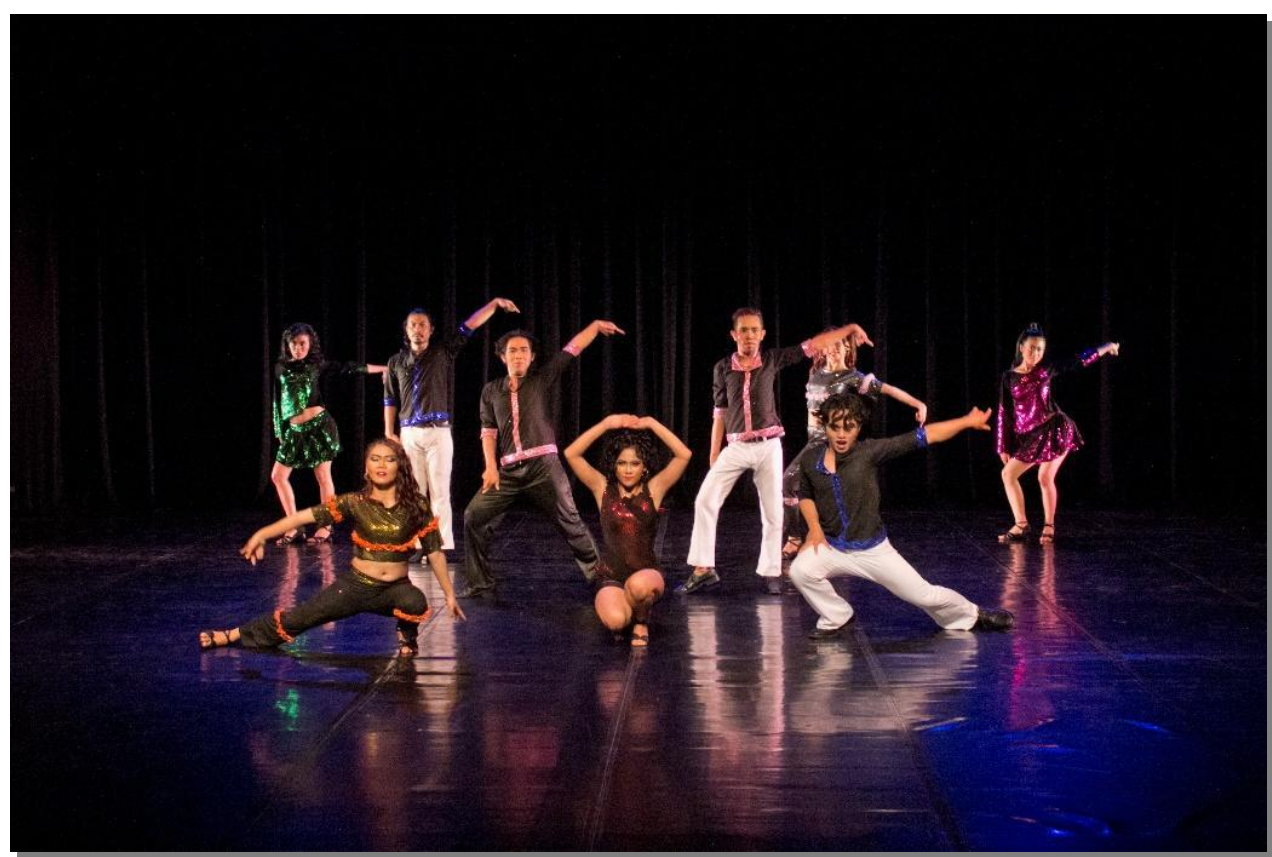

Gambar 1: Adegan III mengambarkan suasana perayaan kemenangan (Foto: Juhinsu, 2015)

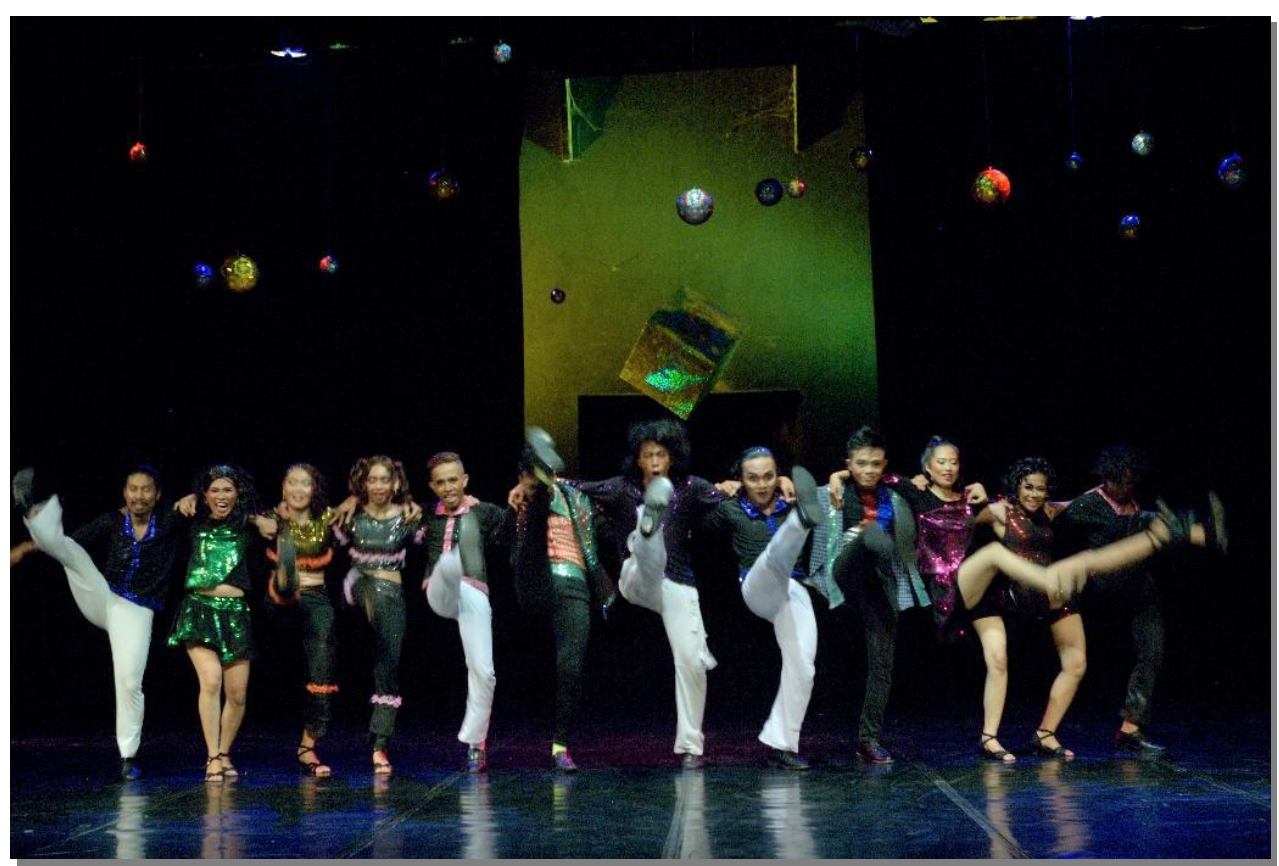

Gambar 2: Salah satu pose Adegan 3 yang juga sebagai akhir pertunjukan. (Foto: Budi, 2016). 


\section{DAFTAR SUMBER ACUAN}

Hadi. Y. Sumandiyo. 2011. Koreografi (Bentuk-Tehnik-Isi). Yogyakarta: Cipta Media

Jones, Randy and Mark Bego. 2009. Macho Man The Disco Era and Gay America's "Coming Out". United State Of America. Greenwood Publishing Group.

Hadi. Y. Sumandiyo. 2011. Koreografi (Bentuk-Tehnik-Isi). Yogyakarta: Cipta Media

\section{SUMBER MEDIA ELEKTRONIK}

Free Genre Of Music dalam artikerl berjudul "Sejarah Asal Mula Musik Disco", 2003, facebook.co.id

\section{SUMBER VIDEOGRAFI}

Disco - Spinning The Story

Disco dance - 1979 - UK Finals (pt1)

Madonna Confession On The Dance Floor 2006

Madonna Sweet Candy 2012

Tomorrowland 2014 Aftermovie 